\title{
COMPATIBILITY STUDY OF FAMOTIDINE WITH SOME PHARMACEUTICAL EXCIPIENTS USING DIFFERENT TECHNIQUES
}

\author{
A. S. Ali Ibrahim, M. A. Hassan*, M. G. Abd El-Mohsen and S. M. El-Shanawany \\ Department of Pharmaceutics, Faculty of Pharmacy, Assiut University, Assiut, Egypt
}

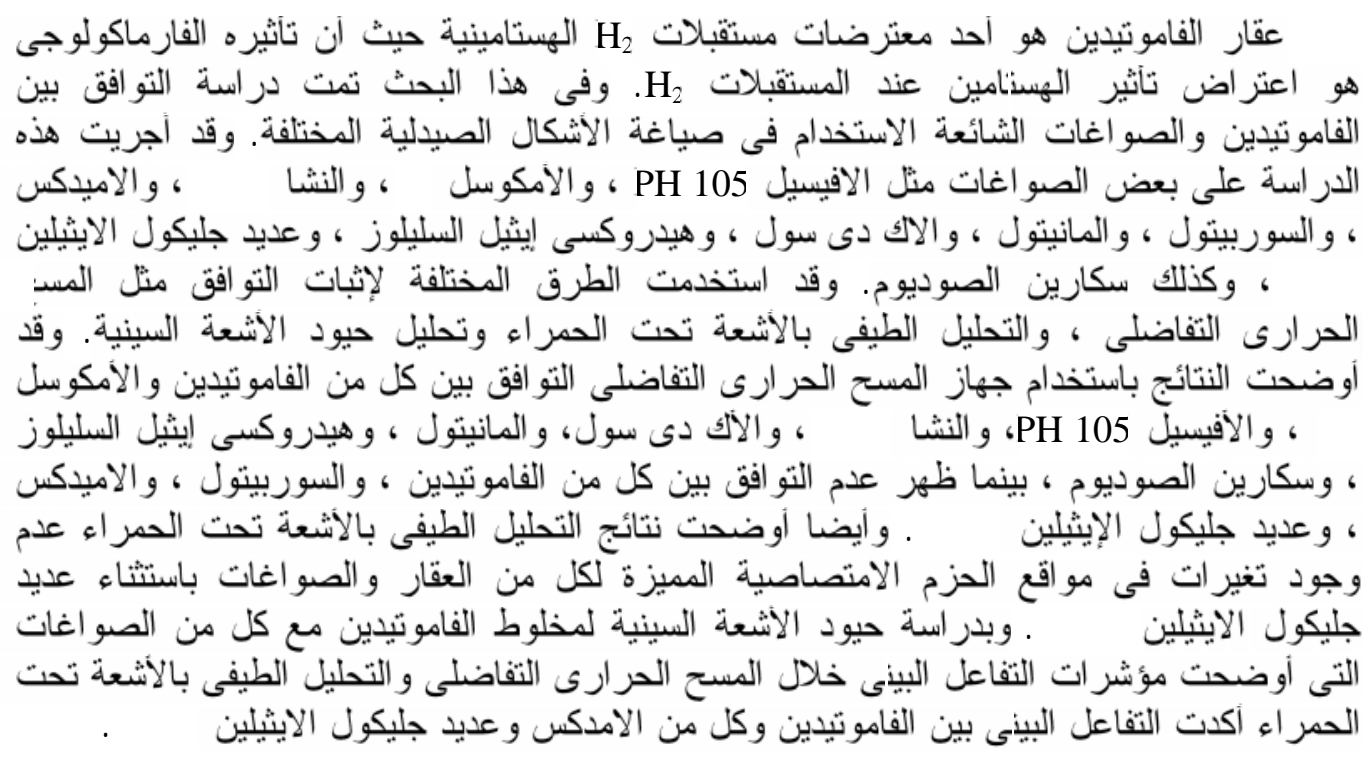

Famotidine is a member of $\mathrm{H}_{2}$-receptor antagonist drug, which pharmacological action primarily involves antagonism of the action of histamine at its $\mathrm{H}_{2}$-receptors. The incompatibility between famotidine and some commonly used tablet excipients was studied. The investigation was made on Avicel PH 105, Emcocel 90, starch 1500 (Sta-Rx 1500), Emdex, sorbitol, mannitol, cross linked sodium carboxymethylcellulose (Ac-Di-sol), PEG6000, hydroxyethylcellulose (HEC) (natrosol) and saccharin sodium. The investigation is made by $D S C, I R$ and X-ray diffraction analysis. The DSC analysis indicated that there was no interaction between famotidine with Emcocel 90, Avicel PH 105, starch 1500, Ac-Di-sol, mannitol, HEC (natrosol) and saccharin sodium. On the other hand DSC indicated an incompatibility between famotidine and sorbitol, Emdex and PEG6000. The study of IR indicated the interaction between famotidine and PEG6000. X-ray diffraction study was carried out on excipients that showed possible interaction with famotidine during the DSC investigations. Only interaction between famotidine, Emdex and PEG6000 was confirmed.

\section{INTRODUCTION}

Famotidine is a histamine $\mathrm{H}_{2}$-receptor antagonist drug. Unlike the earlier histamine $\mathrm{H}_{2}$-receptor antagonists, burimamide, metiamid, cimetidine and ranitidine, famotidine contains a quanidine substituted thiazol ring rather than an imidazol- or furan ring. ${ }^{1}$

Received in 5/5/2004 \& Accepted in 18/9/2004

${ }^{*}$ Corresponding author.<smiles>NC(N)=Nc1nc(CCCC/C(N)=N/S(N)=O)cs1</smiles>

Fig. 1a: $\mathrm{N}^{2}$-(aminosulphonyl)-3-[[[2-[cdiaminomethylene)amino]-thiazol-4-yl]methyl]thio]propanamidine. 
The therapeutic application of this antagonism is the treatment of disorders ranging from hyperacidity, heart burn to peptic ulcer disease, Zolinger-Ellison syndrome, gastroeosphogeal reflux disease, acute stress ulcer and erosion. ${ }^{2}$ The use of $\mathrm{H}_{2}$-receptor antagonists in the treatment of acid peptic disorders depends on the fact that histamine plays an important role in the regulation of gastric acid secretion by the parietal cells. ${ }^{3}$ Inhibition of histamine receptors by $\mathrm{H}_{2-}$ receptor antagonists results in a decrease of both volume and concentration of acid gastric secretions, while changes in pepsin secretion are proportional to gastric acid volume output. ${ }^{4}$ The $\mathrm{H}_{2}$-receptor antagonists activity of famotidine is slowly reversible since the drug dissociates slowly from the $\mathrm{H}_{2}$-receptors. ${ }^{5}$ It was found that famotidine is approximately 7.5 times more potent than ranitidine and 20 times more potent than cimetidine on an equimolar basis. Therapeutic trials indicated that $20 \mathrm{mg}$ twice daily or $40 \mathrm{mg}$ at bed time is as effective as $800 \mathrm{mg}$ daily of cimetidine or $300 \mathrm{mg}$ daily of ranitidine in healing duodenal ulcers. ${ }^{6}$

Famotidine crystallized from different solvent mixtures, was found to exist in three crystalline forms, A, B and C, depending on the solvent system used, which melt at $171.3^{\circ}$, $166.4^{\circ}$ and $160.9^{\circ}$ respectively. The $\mathrm{B}$ form, which is the commercial form of famotidine is probably the most stable and has the lowest aqueous solubility $(0.55 \mathrm{mg} / \mathrm{ml}){ }^{7}$

Drug excipients are pharmacologically inert materials that are added to active ingredients to improve their physicochemical properties and facilitate their formulation into suitable dosage forms. ${ }^{8}$ These excipients can affect drug properties by affecting solubility, stability, bioavailability, patient acceptability and even manufacturing production cost. ${ }^{9}$ This fact makes a careful selection of an excipient a very important step during the preformulation studies. Study of drug-excipient interaction is essential in the initial formulation of a product, and later during processing scale up. ${ }^{9}$

The aim of this work is the elucidation of any physicochemical interactions between famotidine and some commonly used excipients in tablet formulation using differential scanning calorimetry (DSC), IR analysis and X-ray diffraction analysis.

\section{MATERIALS AND METHODS}

\section{Materials and equipment}

Famotidine (Merck and Co. Inc.), Avicel PH 105 (Seppic, France), Sorbitol, Mannitol, cross linked sodium carboxymethylcellulose (Ac-Di-sol) (Cooperation Pharmaceutique Franciase, France), Emdex (Spci, France), Emcocel (Mendell, USA), PEG6000 (Serva, Germany), starch 1500 (Sta-Rx 1500) and HEC (natrosol) (Hercules, France). Differential scanning calorimeter (DSC) (Shimadzu DSC50, Japan), Infrared Spectrometer (Shimadzu IR-470, Japan) and X-ray diffractometer (Philips model PW 1700, Holand).

\section{Preparation of samples}

Physical mixtures of famotidine and each excipient were prepared in $1: 1 \mathrm{w} / \mathrm{w}$ ratio by gently mixing in a glass mortar with a spatula at room temperature. Coground mixtures were obtained by grinding a portion of each physical mixture with a pestle for approximately 10 minutes.

\section{Differential scanning calorimetry study (DSC)}

Samples weighing 5-10 mg were sealed in flat bottomed aluminum pans and heated under an atmosphere of nitrogen. A heating rate of $10 \%$ min was employed over a temperature range of $30-250^{\circ}$. An empty aluminum pan was used as a reference.

\section{Infrared spectroscopy (IR)}

Samples were mixed with $\mathrm{KBr}$ and compressed into disc using a hydrolic pump under pressure of about 5 ton. The spectra were recorded over a range of 4000-300 $\mathrm{cm}^{-1}$.

\section{X-ray diffraction}

The powder samples were scanned over a $2 \theta$ range of $4^{\circ}$ to $60^{\circ}$, with a scanning speed of $0.6 \% \mathrm{~min}$. A cupper anode target at wavelength $1.5418 \AA$ was employed. The instrument utilized a special software program to analyze peak position and intensities. 


\section{RESULTS AND DISCUSSION}

\section{Differential scanning calorimetry study (DSC)}

During DSC, differences in heat flow between a sample and a reference are measured as a function of time and sample temperature. DSC analysis allows quantitative and qualitative information to be obtained about the physical and chemical changes that occur in sample. DSCs are used extensively in the pharmaceutical industry to determine the melting points, purity and glass transition temperatures of materials.

The DSC thermogram of famotidine (Figure 1b) shows that famotidine has one sharp melting endotherm with an onset (thaw point) of $156^{\circ}$ and a peak occurs at $163.1^{\circ}$. The enthalpy of fusion $(\Delta \mathrm{H})$ was calculated to be $129 \mathrm{~mJ} / \mathrm{mg}$. Grinding of famotidine gives a deviation in its characteristic endotherm. The DSC thermogram of ground famotidine shows a sharp endothermic peak with thaw point at $153^{\circ}$ and maximum at $163.4^{\circ}$. The value of $\Delta H$ was found to be $-132 \mathrm{~mJ} / \mathrm{mg}$ (Table 1).

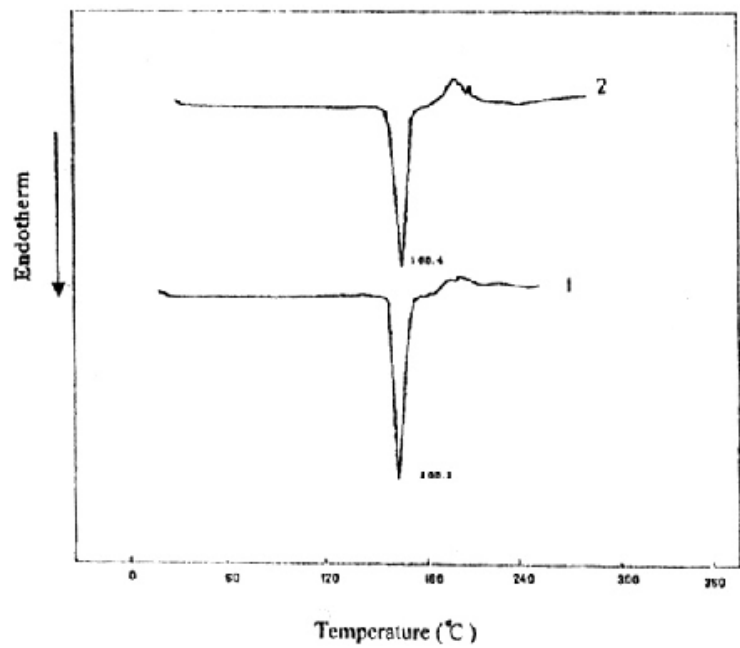

Fig. 1b: DSC thermograms of famotidine (1) and ground famotidine (2).

When two substances are mixed, the purity of each may be reduced and generally slightly lower melting endotherms result. If the solid-solid interaction is extremely weak or non existent, the reduction of the melting point is usually inconsequential. On the other hand, any large shift in the melting point signifies that solid-solid interaction has occurred, although it does not necessarily indicate an incompatibility. ${ }^{10}$

Studying the DSC thermograms of different excipients revealed that Avicel $\mathrm{PH}$ 105, Emcocel 90, starch 1500, Ac-Di-sol, and saccharin sodium (Figs. 2-6) showed a shallow broad endotherm between $40^{\circ}$ and $110^{\circ}$. This can be attributed to the volatilization of the adsorbed water. $^{10,11}$ The combination of famotidine with Emcocel 90, Avicel PH 105 and AC-Di-sol regardless of the method of sample preparation produced thermograms exhibit the same characteristic features of the endothermic peak of famotidine and excipients. Furthermore, no important effect on either the temperature of drug melting peak, or the enthalpy value per unit mass of famotidine due to sample treatment were seen, confirming the absence of incompatibility.

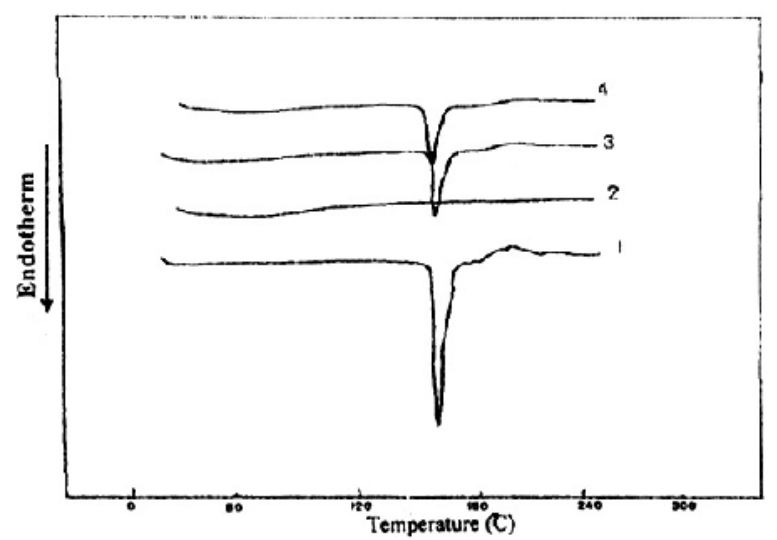

Fig. 2: DSC thermograms of famotidine (1), Emcocel 90 (2), simplex mixture (3) and ground mixture (4).

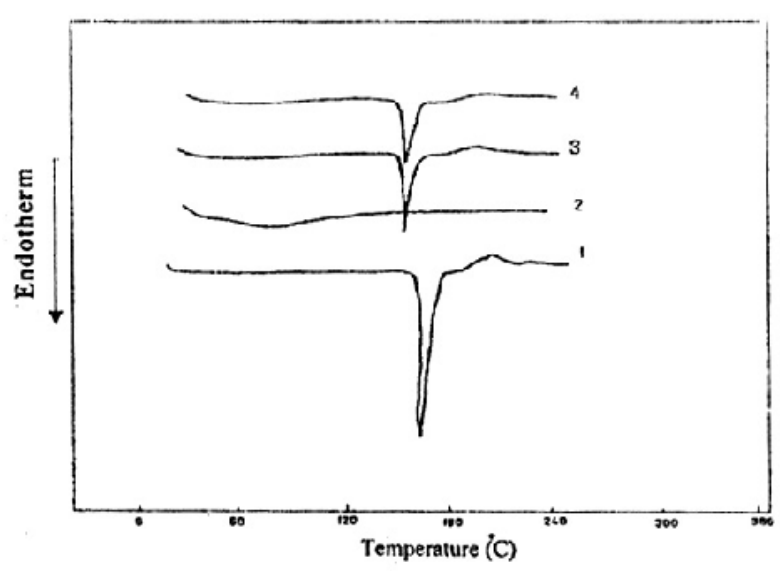

Fig. 3: DSC thermograms of famotidine (1), Avicel PH 105 (2), simple mixture (3) and ground mixture (4). 
Table 1: Effect of different excipients on the peak temperature (m.p.) and enthalpy of fusion $(\Delta \mathrm{H})$ of famotidine thermogram.

\begin{tabular}{|c|c|c|c|}
\hline Samples & Thaw point & Peak temperature $\left({ }^{\circ}\right)$ & Enthaly $(\Delta \mathrm{H})(\mathrm{mJ} / \mathrm{mg})$ \\
\hline $\begin{array}{l}\text { Famotidine } \\
\text { Famotidine }(\mathrm{G})\end{array}$ & $\begin{array}{l}156.0 \\
153.7\end{array}$ & $\begin{array}{l}163.1 \\
163.4\end{array}$ & $\begin{array}{l}-129 \\
-132 \\
\end{array}$ \\
\hline $\begin{array}{l}\text { Emcocel } 90 \\
F+\text { Emcocel } \\
F+\text { Emcocel }(G)\end{array}$ & $\begin{array}{c}- \\
158.1 \\
153.0\end{array}$ & $\begin{array}{c}- \\
164.6 \\
162.7\end{array}$ & $\begin{array}{c}- \\
-63.24 \\
-54.73\end{array}$ \\
\hline $\begin{array}{l}\text { Starch } 1500 \\
F+\text { Starch } 1500 \\
F+\text { Starch } 1500(\mathrm{G}) \\
\end{array}$ & $\begin{array}{c}- \\
154.6 \\
155.3 \\
\end{array}$ & $\begin{array}{c}- \\
164.3 \\
162.8 \\
\end{array}$ & $\begin{array}{r}- \\
-64.56 \\
-43.54 \\
\end{array}$ \\
\hline $\begin{array}{l}\text { Avicel PH } 105 \\
\text { F + Avicel PH } 105 \\
\text { F + Avicel PH } 105 \text { (G) }\end{array}$ & $\begin{array}{c}- \\
158.6 \\
154.5\end{array}$ & $\begin{array}{c}- \\
163.9 \\
163.4\end{array}$ & $\begin{array}{c}- \\
-64.20 \\
-56.73\end{array}$ \\
\hline $\begin{array}{l}\text { Ac-Di-sol } \\
\text { F + Ac-Di-sol } \\
\text { F + Ac-Di-sol (G) }\end{array}$ & $\begin{array}{r}- \\
157.6 \\
155.3 \\
\end{array}$ & $\begin{array}{c}- \\
164.8 \\
163.1 \\
\end{array}$ & $\begin{array}{r}- \\
-64.97 \\
-42.59 \\
\end{array}$ \\
\hline $\begin{array}{l}\mathrm{HEC} \\
\mathrm{F}+\mathrm{HEC} \\
\mathrm{F}+\mathrm{HEC}(\mathrm{G}) \\
\end{array}$ & $\begin{array}{c}- \\
153.5 \\
150.1 \\
\end{array}$ & $\begin{array}{r}- \\
163.8 \\
161.2 \\
\end{array}$ & $\begin{array}{r}- \\
-39.77 \\
-17.89 \\
\end{array}$ \\
\hline $\begin{array}{l}\text { Emdex } \\
F+\text { Emdex } \\
F+\operatorname{Emdex}(G)\end{array}$ & $\begin{array}{l}57.8,134,194 \\
61.8,129,155 \\
55.8,116,151\end{array}$ & $\begin{array}{c}85,152.8,218 \\
83,141.2,158.3 \\
74.2,131.6,154.7\end{array}$ & $\begin{array}{l}- \\
- \\
-\end{array}$ \\
\hline $\begin{array}{l}\text { Sorbitol } \\
\text { F + sorbitol } \\
\text { F + sorbitol }(\mathrm{G}) \\
\end{array}$ & $\begin{array}{c}78.3 \\
80.5,117.2 \\
84.4,117.6 \\
\end{array}$ & $\begin{array}{c}97.8 \\
96.6,136.4 \\
97.7,133.7 \\
\end{array}$ & $\begin{array}{c}-170.1 \\
-89.2,-48.08 \\
-94.54,-30.9 \\
\end{array}$ \\
\hline $\begin{array}{l}\text { Mannitol } \\
\text { F + Mannitol } \\
\text { F + Mannitol (G) }\end{array}$ & $\begin{array}{l}157.2 \\
145.0 \\
138.0\end{array}$ & $\begin{array}{l}168.6 \\
152.0 \\
150.5\end{array}$ & $\begin{array}{l}-240.3 \\
-187.3 \\
-208.7\end{array}$ \\
\hline $\begin{array}{l}\text { Saccharin sodium } \\
\text { F + Saccharin sodium } \\
\text { F + Saccharin sodium }(\mathrm{G})\end{array}$ & $\begin{array}{c}113.1 \\
113.3,155.3 \\
110,148.6 \\
\end{array}$ & $\begin{array}{c}119.2 \\
119,161.1 \\
120.1,156.4 \\
\end{array}$ & $\begin{array}{c}-158.1 \\
-74.8,-60.7 \\
-69.9,-60.1 \\
\end{array}$ \\
\hline $\begin{array}{l}\text { PEG6000 } \\
\text { F + PEG6000 } \\
\text { F + PEG6000 (G) }\end{array}$ & $\begin{array}{l}54.1 \\
54.1 \\
50.1\end{array}$ & $\begin{array}{l}16.1 \\
60.8 \\
59.5\end{array}$ & $\begin{array}{l}-184.1 \\
-82.25 \\
-83.18\end{array}$ \\
\hline
\end{tabular}
$\mathrm{F}=$ Famotidine
$(\mathrm{G})=$ Ground mixture

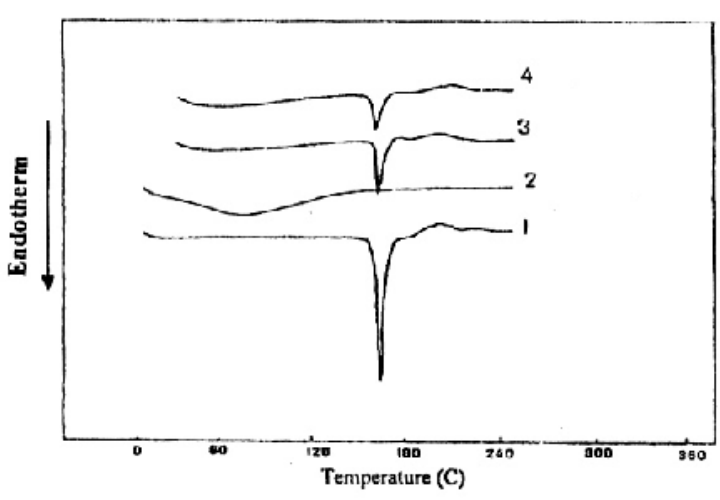

Fig. 4: DSC thermograms of famotidine (1), starch 1500 (2), simple mixture (3) and ground mixture (4).

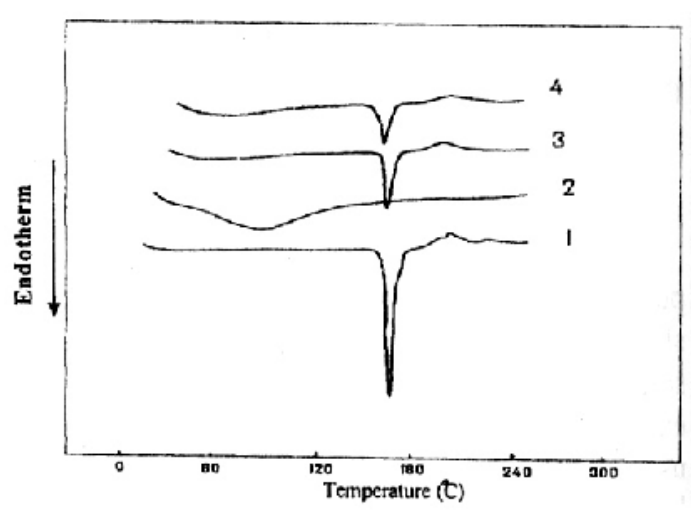

Fig. 5: DSC thermograms of famotidine (1), AcDi-Sol (2), simple mixture (3) and ground mixture (4). 


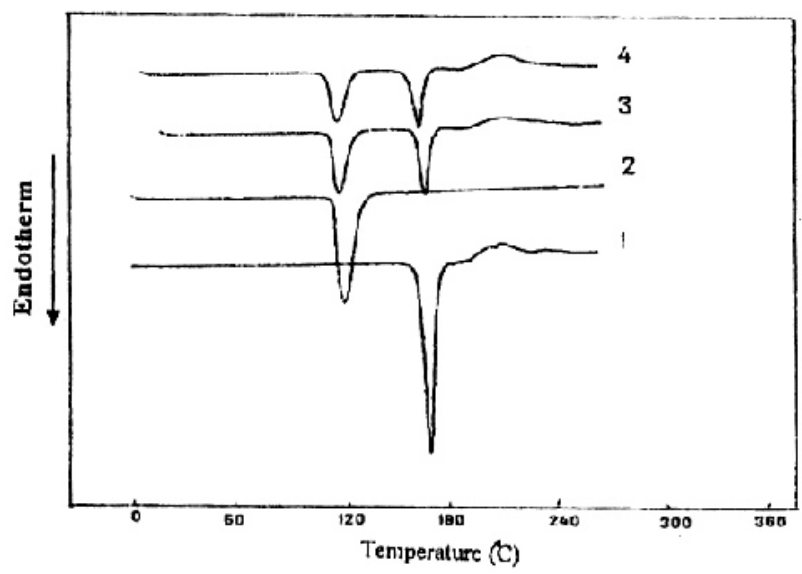

Fig. 6: DSC thermograms of famotidine (1), saccharin sodium (2), simple mixture (3) and ground mixture (4).

The enthalpies of fusion $(\Delta \mathrm{H})$ in all the simple mixtures have a value approximately equals to the predicted value $(-64 \mathrm{~mJ} / \mathrm{mg})$ due to the dilution of famotidine by the excipients (Table 1). The $\Delta \mathrm{H}$ values of the ground mixtures of these excipients are lower than that of the simple mixtures. The decrease in the enthalpy of the overall thermal effect per mass unit is a general observation when the surface of contact between drug and excipients was increased by grinding, compression or kneading. ${ }^{11}$ The results obtained revealed that no incompatibility occurs with the previously mentioned excipients.

The thermograms of famotidinehydroxyethylcellulose simple and ground mixture (Fig. 7) show one endothermic peak at the same position of famotidine characteristic peak and a shallow broad endothermic effect in the range $60-120^{\circ}$. This might correspond to the volatilization of adsorbed water. The enthalpy of fusion $(\Delta \mathrm{H})$ of this peak in the simple mixture is equal to $-39.7 \mathrm{~mJ} / \mathrm{mg}$, and the ground mixture is equal to $-17.8 \mathrm{~mJ} / \mathrm{mg}$, which are lower than that expected from the predicted theoretical value $(-64 \mathrm{~mJ} / \mathrm{mg})$. This observation indicates interaction between famotidine and hydroxyethylcellulose.

Famotidine mixture with either Emdex or PEG6000 (Figs. 8,9), show no deviation in the endothermic peaks of the excipient but there is a complete disappearance of famotidine endothermic peak. The disappearance of the drug melting peak is certainly indicative of an interaction between the drug and the excipient.
Similar effect was observed for other drugs, such as ketoprofen, ${ }^{11}$ naproxen, ${ }^{12}$ diffunisal ${ }^{13}$ and piroxicam ${ }^{14}$ in mixtures with various PEGs was attributed to the dissolution of the drug in the melted polymer.

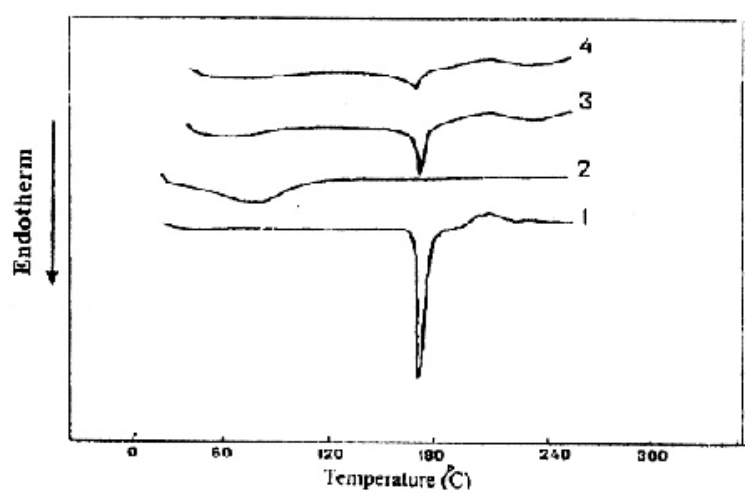

Fig. 7: DSC thermograms of famotidine (1), hydroxyethylcellulose (2), simple mixture (3) and ground mixture (4).

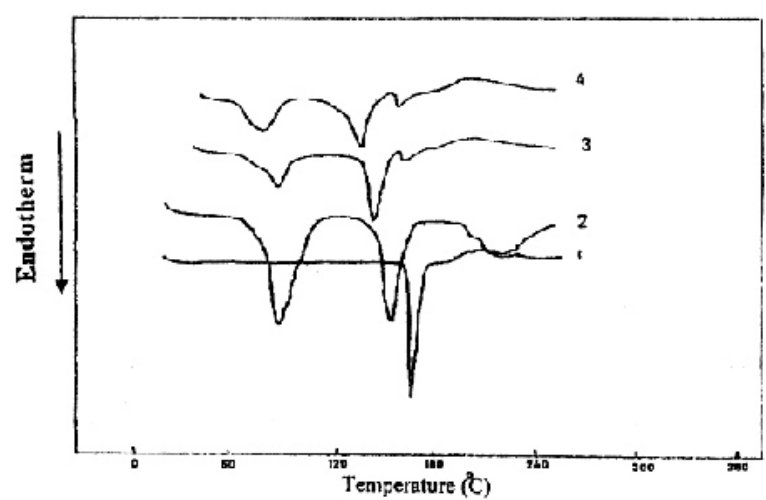

Fig. 8: DSC thermograms of famotidine (1), Emdex (2), simple mixtutre (2) and ground mixture (4).

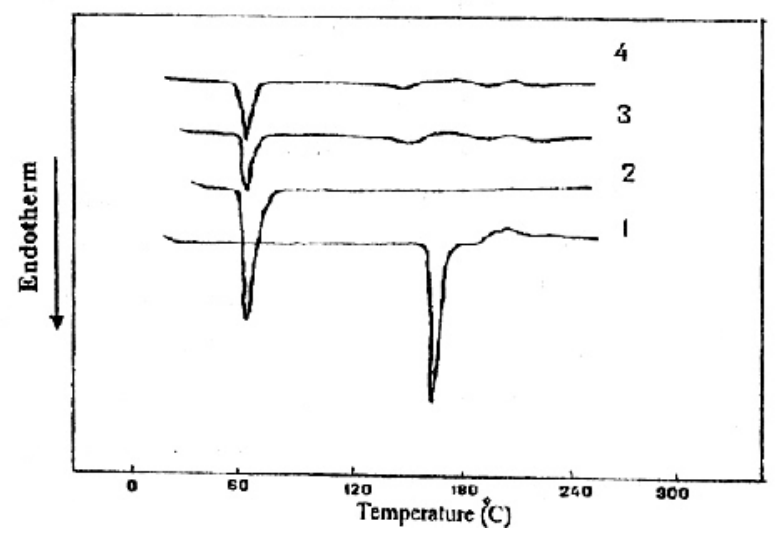

Fig. 9: DSC thermograms of famotidine (1), PEG 6000 (2), simple mixture (3) and ground mixture (4). 
Figure 10 shows the DSC thermograms of sorbitol and famotidine-sorbitol simple and ground mixtures. The figure indicates that sorbitol alone has one endothermic peak at $97.8^{\circ}$. Mixing sorbitol with famotidine either simply or with grinding leads to a reservation of sorbitol peak, while the endothermic peak of famotidine exhibits a shift toward a lower melting point of $136.4^{\circ}$ and $133.7^{\circ}$ for simple and ground mixtures respectively. This down shift is also accompanied with a change in $\Delta \mathrm{H}$ value of the famotidine peak (Table 1), which indicates the presence of an interaction. This result was attributed to partial dissolution of the drug in the melted excipient. ${ }^{15}$

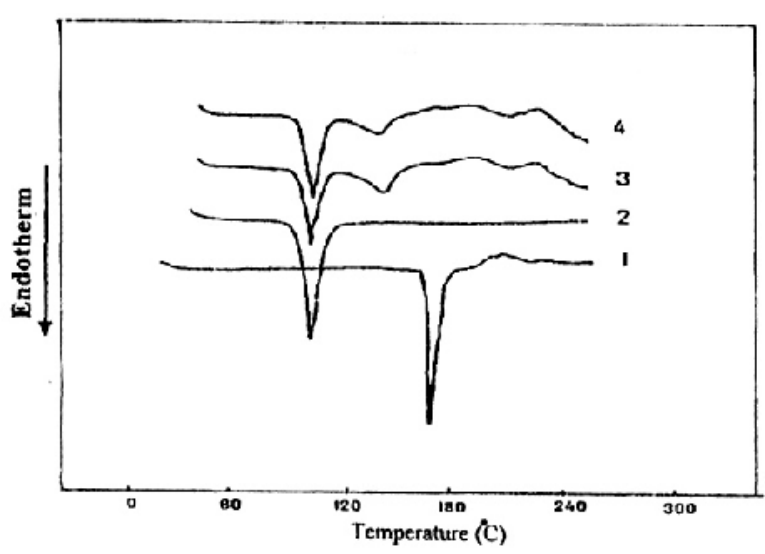

Fig. 10: DSC thermograms of famotidine (1), sorbitol (2), simple mixture (3) and ground mixture (4).

On the other hand, mannitol (Figure 11) has one endothermic peak at $163^{\circ}$, which is very close to the position of famotidine peak. Mixing of mannitol with famotidine leads to a thermogram containing only one peak at $152^{\circ}$. This peak can be considered as a result of overlaping of mannitol and famotidine characteristic peaks. This conclusion is supported by the value of $\Delta \mathrm{H}$, which is equal to $-187 \mathrm{~mJ} / \mathrm{mg}$ in simple mixture and $-208 \mathrm{~mJ} / \mathrm{mg}$ in the ground mixture. These values are approximately equal to the summation of the predicted values of each peak after 1:1 dilution. Shifting of the peak to a lower melting point can be considered normal due to decrease in the purity of the mixture components by mixing with each other.

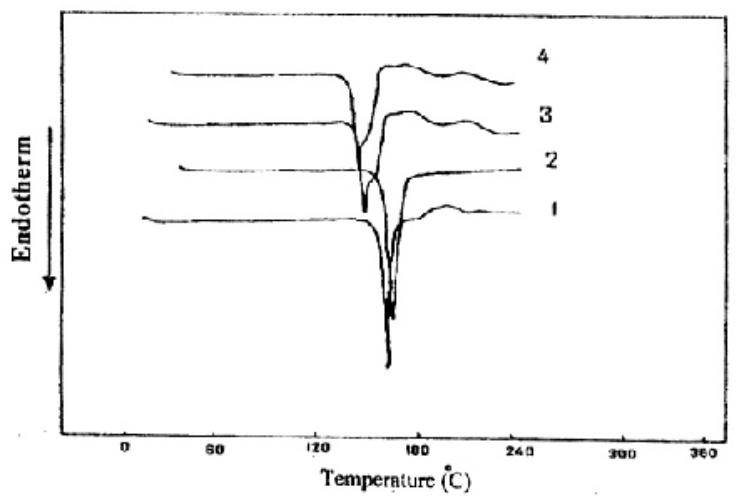

Fig. 11: DSC thermograms of famotidine (1), mannitol (2), simple mixture (3) and ground mixture (4).

The polar character of most of the excipients examined (sorbitol, mannitol and PEG6000) contributed to their interactions with famotidine which has polar structure. This favours the electrostatic interactions between the drug and the excipients tested.

\section{Infrared spectroscopy (IR)}

The infrared spectra of famotidine and 1:1 $\mathrm{w} / \mathrm{w}$ famotidine-excipients simple and ground mixtures were studied. From the structure and the recorded IR spectrum (Fig. 12) famotidine have the following characteristic bands:

$\begin{array}{lc}\text { Assignment } & \text { Wavenumber }\left(\mathrm{cm}^{-1}\right) \\ \text { N-H symmetric } & 3395,3240 \\ \text { stretching } & \\ \text { C-H stretching } & 2970 \\ \mathrm{C}=\mathrm{N} \text { stretching } & 1636 \\ \mathrm{~N}-\mathrm{H} \text { bending } & 1595 \\ -\mathrm{SO}_{2} \text {-sulphonyl } & 1326(\mathrm{~s}), 1159(\mathrm{~s})\end{array}$

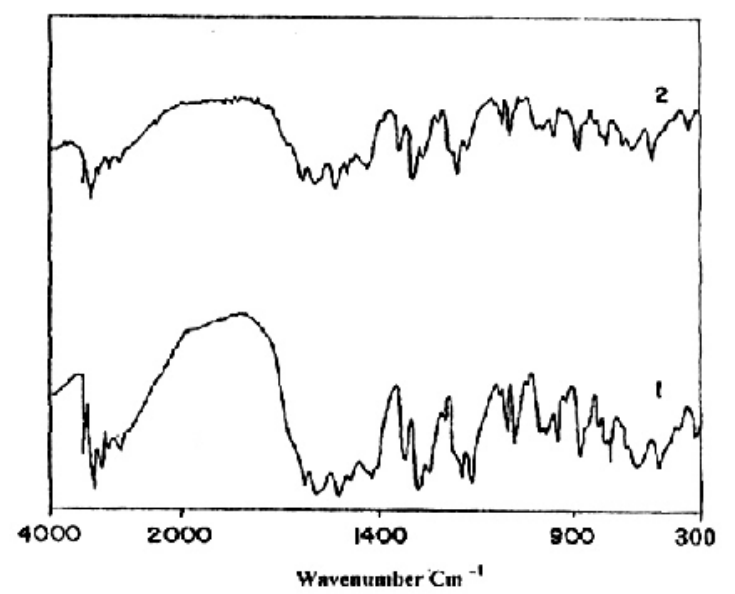

Fig. 12: IR spectra of famotidine (1) and ground famotidine (2). 
The spectrum of ground famotidine (Figure 12) shows that all the characteristic bands of famotidine after grinding are preserved without any changes in their position.

Infrared examination of famotidineexcipients simple and ground mixtures shows no changes in the characteristic bands of both the drug and the excipients, except in the spectrum of famotidine-PEG6000 ground mixture. In this spectrum the band at $2920 \mathrm{~cm}^{-1}$ became stronger (Figure 13). The increase of the intensity of this band can be attributed to the formation of intermolecular hydrogen bonding between the $-\mathrm{OH}$ groups in the PEG6000 and the abundant $-\mathrm{NH}_{2}$ groups of famotidine. This type of association interaction usually leads to shift of the band toward a lower frequency region. ${ }^{16}$

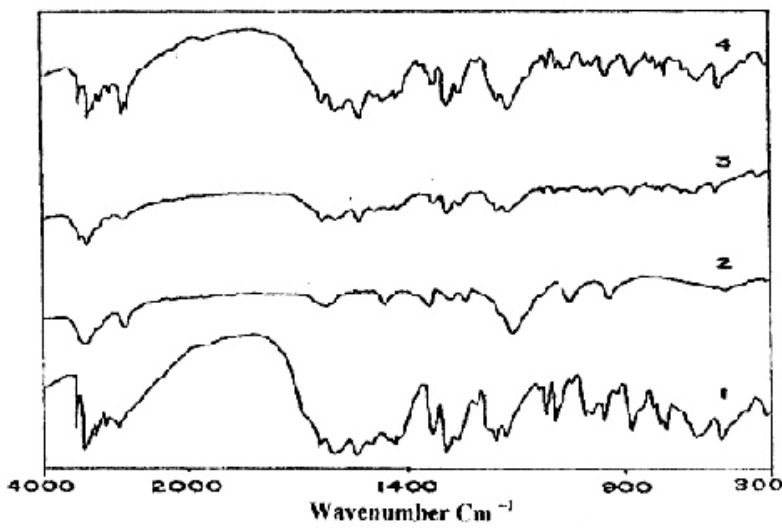

Fig. 13: IR spectra of famotidine (1), PEG 6000 (2), simple mixture (3) and ground mixture (4).

\section{$\mathrm{X}$-ray diffraction}

The DSC thermograms of famotidine mixtures with Emdex, PEG6000 and Sorbitol revealed the presence of possible interaction between famotidine and these excipients. For confirmation of the DSC results, these mixtures were subjected to X-ray diffraction analysis.

The use of X-ray diffraction in studying drug-excipient interaction depends on the fact, which states that in a solid mixture, the powder diffraction pattern of each crystalline phase is produced independently of the other constituents. Thus the diffraction patterns of a powder mixture will be the summation of the diffraction patterns of the individual constituents. ${ }^{17}$
X-ray diffraction pattern of famotidine untreated sample and ground famotidine (Figure 14) shows changes in the relative intensities of famotidine characteristic peaks. There is no appearance of new peaks or disappearance of any of these peaks (Table 2). Grinding pressure has the ability to induce phase transformation. ${ }^{17}$ Hassan et al investigated the X-ray diffractograms of famotidine polymorphs and found a great differences in respect to both position and intensity of the diffractions between the three polymorphic forms. ${ }^{7}$ This means that the observed changes in the relative intensities of famotidine peaks were not due to polymorphic changes. In general, the shape of many crystalline particles tend to give a specimen that exhibits some degree of preferred orientation in the specimen which in turn affect the relative intensities of the reflections. ${ }^{17}$

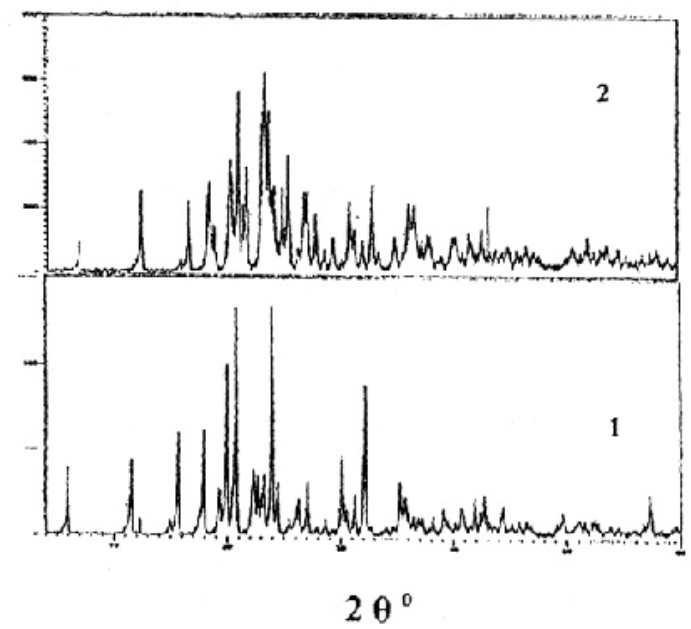

Fig. 14: X-ray diffractograms of famotidine (1) and ground famotidine (2).

X-ray diffractograms of famotidine simple mixtures with the selected excipients showed that the entire characteristic peaks of famotidine were preserved in their specific positions. These peaks were exposed to an alteration in their relative intensities (Table 3). Absence of new characteristic peaks could be enough to exclude the idea of presence of interactions result in new crystalline compounds. The changes were observed only in the intensities of famotidine peaks, which indicates that famotidine was not subjected to polymorphic changes. 
Table 2: Effect of grinding on the relative intensities of famotidine characteristic peaks.

\begin{tabular}{|c|c|c|c|c|c|c|c|c|}
\hline Sample & \multicolumn{8}{|c|}{ Relative intensity } \\
\hline Famotidine & 100 & 100 & 75 & 67 & 46 & 45 & 26 & 19 \\
\hline Famotidine (G) & 90 & 42 & 56 & 17 & 45 & 8 & 100 & 81 \\
\hline
\end{tabular}

$(\mathrm{G})=$ Ground

Table 3: Effect of simple mixing of famotidine with different excipients on the relative intensities of its characteristic peaks.

\begin{tabular}{|l|c|c|c|c|c|c|}
\hline \multicolumn{1}{|c|}{ Sample } & \multicolumn{7}{c|}{ Relative intensity } \\
\hline Famotidine & 100 & 100 & 75 & 67 & 46 & 45 \\
\hline F + Emdex & 73 & 52 & 100 & 49 & 26 & 37 \\
\hline F + sorbitol & 69 & 54 & 100 & 55 & 32 & 47 \\
\hline F + PEG6000 & 34 & 30 & 34 & 23 & 15 & 17 \\
\hline
\end{tabular}

On the other hand, X-ray diffractograms of famotidine ground mixtures with the excipients under investigation show some deviations from the results obtained from diffractograms of the simple mixtures. Grinding famotidine with sorbitol, and hydroxyethylcellulose (HEC) lead only to changes in the relative intensities of famotidine characteristic peaks relative to those observed in the X-ray diffraction pattern of the ground famotidine alone (Table 4).

X-ray diffraction pattern of famotidine Emdex ground mixtures shows a disappearance of two of the characteristic peaks of famotidine, which exist at $d$-space of 4.26 and 3.77 (Table 4). The X-ray diffractogram of famotidine PEG6000 shows also a disappearance of one of famotidine peaks that exists at $d$-space of 3.51 (Table 4). Disappearance of famotidine peaks can indicate the presence of interaction between the drug and the excipients. The IR spectrum of famotidine - Emdex ground mixture did not show any alteration indicative to the presence of interaction, which rise the suggestion that grinding famotidine with Emdex may lead to alteration in the polymorph of famotidine.

Grinding of famotidine with each of Emdex and sorbitol leads to appearance of one new peak in their X-ray diffractograms at $d$ space range 3.98-4.00 with relative intensity of 69 and $75 \%$ respectively (Figures 15,16). This peak does not exist in any of the X-ray diffractograms of the previously mentioned excipients or in that of the ground famotidine, but exist with low relative intensity of $28 \%$ in the X-ray diffractogram of the unground famotidine sample. As mentioned before, size reduction of the drug crystals can affect the preferred orientation in the specimen, which in turn affects the relative intensities of the reflection. ${ }^{17}$

Investigation of the effect of the presence of famotidine on the excipients X-ray diffraction patterns indicated that Emdex, and sorbitol preserve their own characteristic peaks with a minor changes in the relative intensities. Hydroxyethylcellulose is an amorphous compound as indicated by the absence of peaks in its diffractogram. Mixing of this excipient with famotidine either simply or with the aid of grinding results of X-ray diffractograms similar to those of famotidine and ground famotidine respectively.

X-ray diffractogram of PEG6000 famotidine simple mixture shows a disappearance of two characteristic peaks of PEG6000, which are present at $d$-space of 3.32 and 2.49. The ground mixture exhibits also a disappearance of two PEG6000 characteristic peaks that present at $d$-space of 4.03 and 3.32, beside the disappearance of one of famotidine characteristic peaks (Table 4). Taking into consideration that both DSC thermograms and IR spectra of famotidine PEG6000 mixtures revealed the presence of interaction, it can be concluded that mixing of famotidine with PEG6000 leads to strong interaction, which affect the drug as well as the excipient (Figure 17). 
Table 4: Effect of grinding of famotidine with different excipients on the relative intensities of its characteristic peaks.

\begin{tabular}{||l|c|c|c|c|c|c||}
\hline \multicolumn{1}{|c|}{ Sample } & \multicolumn{7}{c||}{ Relative intensity } \\
\hline Famotidine (G) & 100 & 90 & 81 & 81 & 59 & 56 \\
\hline F + Emdex & 27 & - & 32 & - & 30 & 70 \\
\hline F + sorbitol & 54 & 32 & 47 & 43 & 57 & 79 \\
\hline F + PEG6000 & 84 & 93 & 100 & 63 & 68 & 69 \\
\hline
\end{tabular}

$\mathrm{F}=$ Famotidine

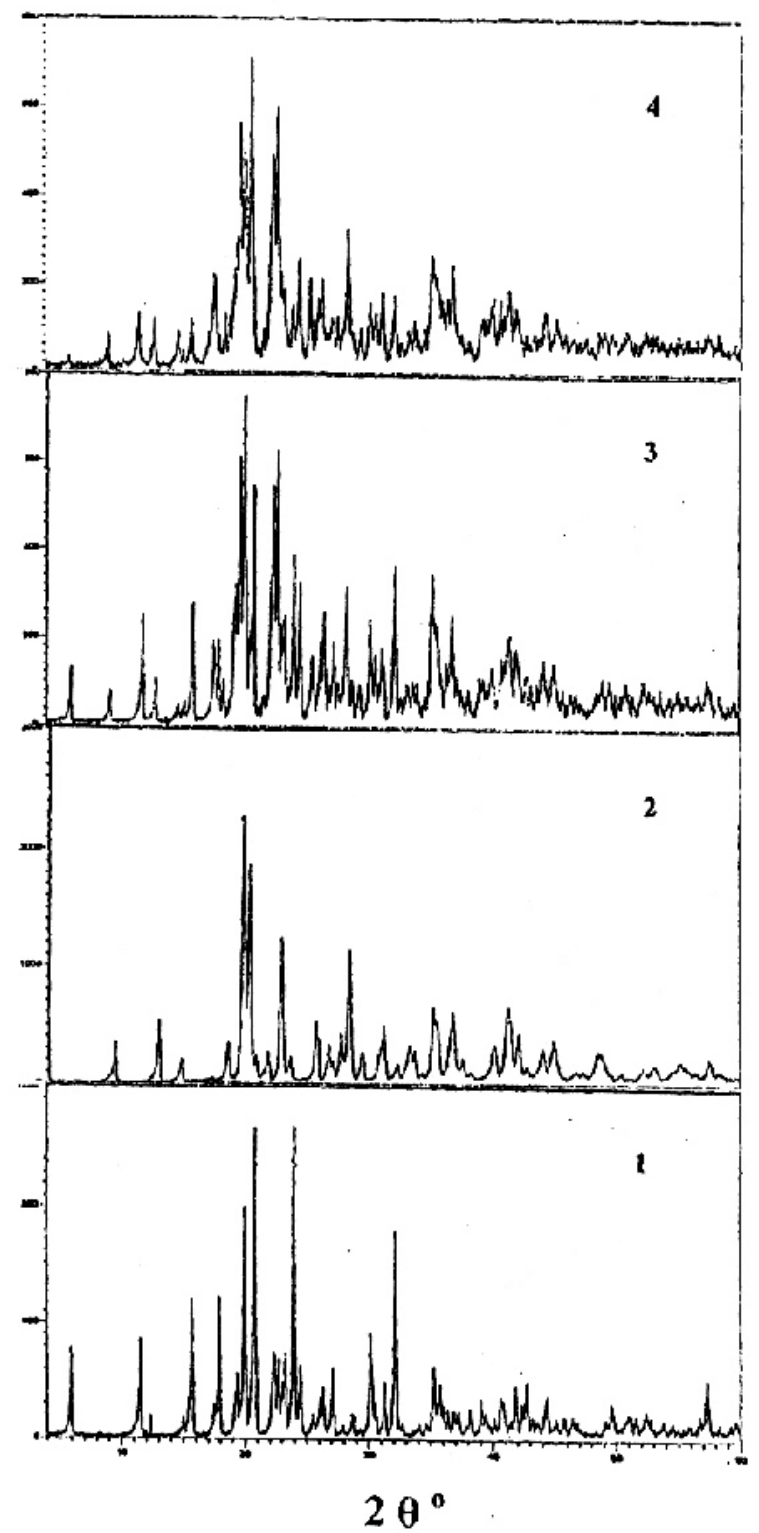

Fig. 15: X-ray diffractograms of famotidine (1), Emdex (2), simiple mixture (3) and ground mixture (4).

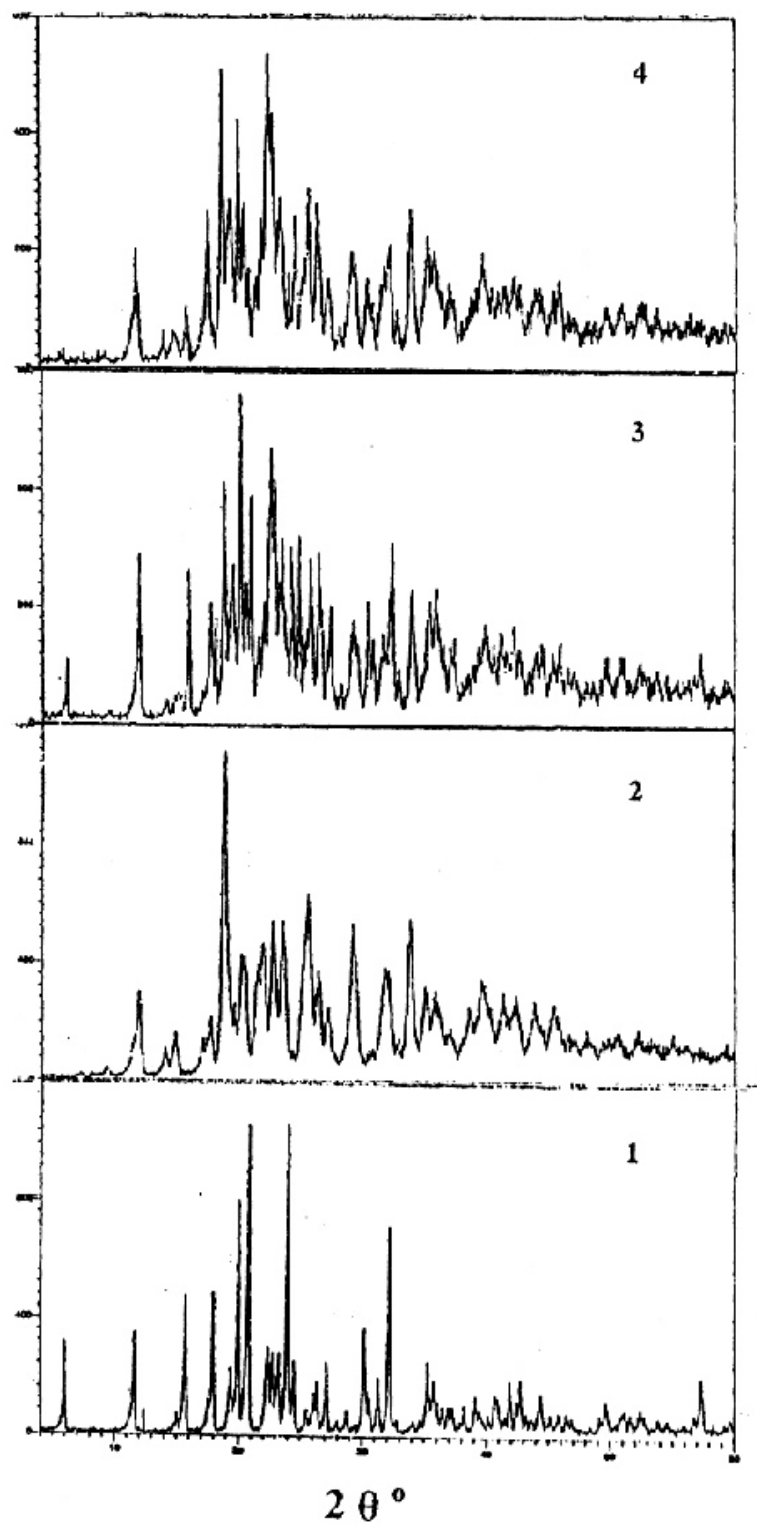

Fig. 16: X-ray diffractograms of famotidine (1), sorbitol (2), simiple mixture (3) and ground mixture (4). 


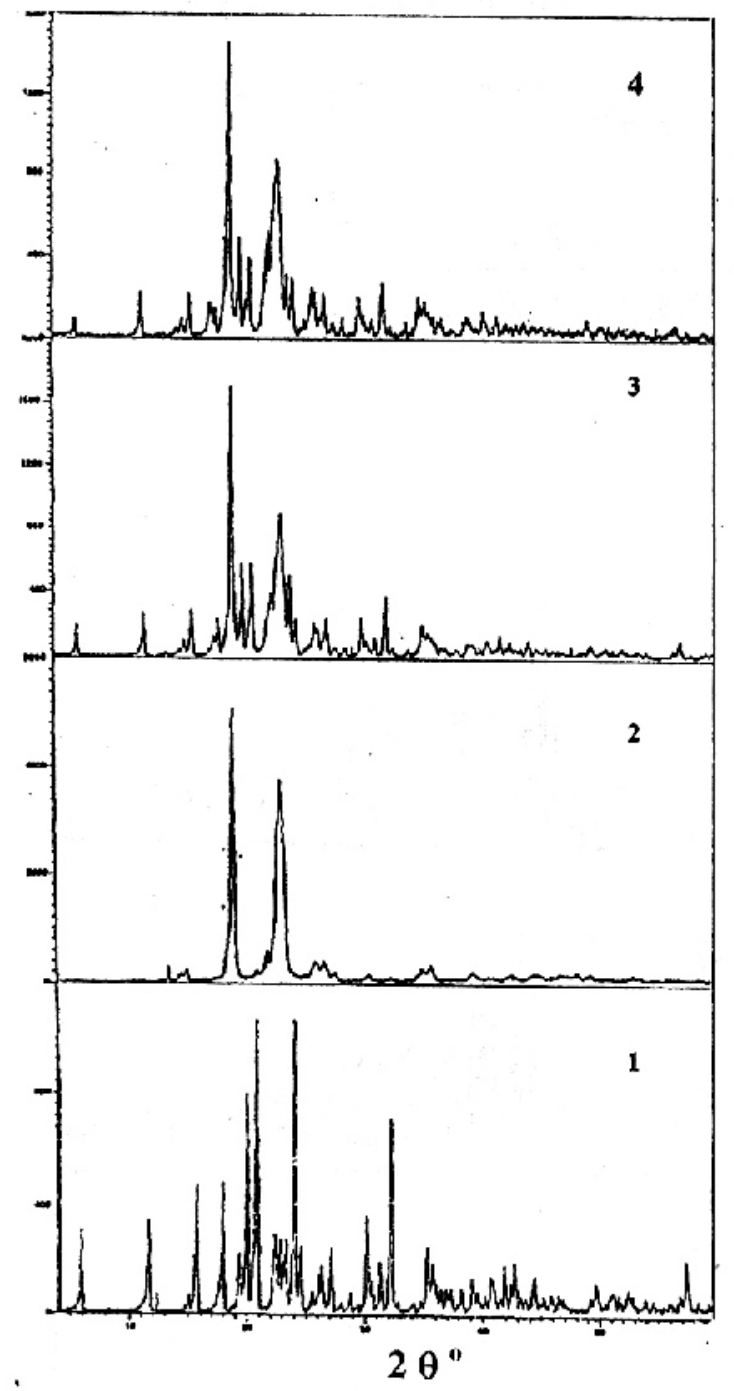

Fig. 17: X-ray diffractograms of famotidine (1), PEG 6000 (2), simiple mixture (3) and ground mixture (4).

\section{Conclusion}

From the previous study it was concluded that: Famotidine-excipients compatibility study revealed that the drug is compatible with each of Emcocel 90, Avicel PH 105, starch 1500, Ac-Di-sol, mannitol and saccharin sodium.

The DSC study revealed the presence of possible interactions between famotidine and each of Emdex, sorbitol, PEG6000 and hydroxyethylcellulose. Interaction of famotidine with Emdex and PEG6000 was confirmed by X-ray diffraction. While the IR spectral analysis confirmed only the interaction between the drug and PEG6000.

Studies of famotidine dissolution rate and aqueous solubility in the presence of different excipients revealed no adverse effects of the observed interactions on the previous two parameters.

\section{REFERENCES}

1- Merck Sharp and Dohme, Pepcid prescriping information. West Point, PA, Dec., (1991).

2- J. N. Delgado and W. A. Remers, "Organic Medicinal and Pharmaceutical Chemistry", New York, $10^{\text {th }}$ edn., 1998, pp. 676-80.

3- A. W. Herling and K. Weidmann, "Gastric Proten Pump Inhibitors. In: Burger's Medicinal Chemistry and Drug Discovery", Wolff, M.E. (ed.). New York, $5^{\text {th }}$ edn., Vol. 2, 1996, pp. 120-25.

4- M. Gray and L. A. Noueihed, (eds.), "PDR Generic, The Information Standard for Prescription Drugs", New Jersey, $3^{\text {rd }}$ edn., 1997, pp. 1297-300.

5- R. G. Pendleton, M. L. Torchiana and C. Chung, Arch. Int. Pharmacodyn., 266, 416 (1983).

6- R. R. Beradi, R. M. Tankanow and T. T. Nostrant, Clin. Pharm., 7 (4), 271-84 (1988).

7- M. A. Hassan, M. S. Salem, M. S. Sueliman and N. M. Najib, Int. J. Pharm., 149, 227-32 (1997).

8- F. J. Bandelin, "Compressed tablets by wet granulation. In: Pharmaceutical Dosage Forms: Tablets", H. A. Lieberman, L. Lachman, and J. B. Schwartz, (eds.), New York, $2^{\text {nd }}$ ed., Vol. 1, 1989, pp. 15179.

9- L. L. Augsburger and M. J. Zellhofer, "Tablet Formulation. In: Encyclopedia of Pharmaceutical Technology", J. Swarbrick and J. C. Boylan, (eds), New York, $2^{\text {nd }}$ edn., Vol. 14, 1990, pp. 389-401.

10- S. A. Botha and A. P. Lötter, Drug Dev. Ind. Pharm., 16 (4), 673-83 (1990).

11- P. Mura, A. Manderioli, G. Bramanti, S. Furlanetto and S. Pinzauti, Int. J. Pharm., 119, 71-79 (1995).

12- P. Mura, G. P. Bettinetti, G. Bramanti and A. Manderioli, Acta of Symposium on Pharmacy and Thermal Analysis, Freiburg, 10 (1993).

13- M. N. Najib and M. S. Suleiman, Int. J. Pharm., 51, 225-32 (1989). 
14- M. Fernandez, I. C. Rodriguez, M. V. Margarit and A. Cerezo, Int. J. Pharm., 84, 197-202 (1992).

15- P. Mura, M. T. Faucci, A.. Manderioli, S. Furlanetto and S. Pinzauti, Drug Dev. Ind. Pharm., 24 (8), 747-56 (1998).
16- D. H. Williams and I. Fleming, (eds.), "Spectroscopic Methods in Organic Chemistry", England, $3^{\text {rd }}$ edn., 1972, p. 30.

17- R. Surxanarayanan and S. Rastogi, "X-ray Powder Diffractometry. In: Encyclopedia of Pharmaceutical Technology", J. Swarbrick and J. C. Boylan, (eds.), 2002, pp. 305-19. 